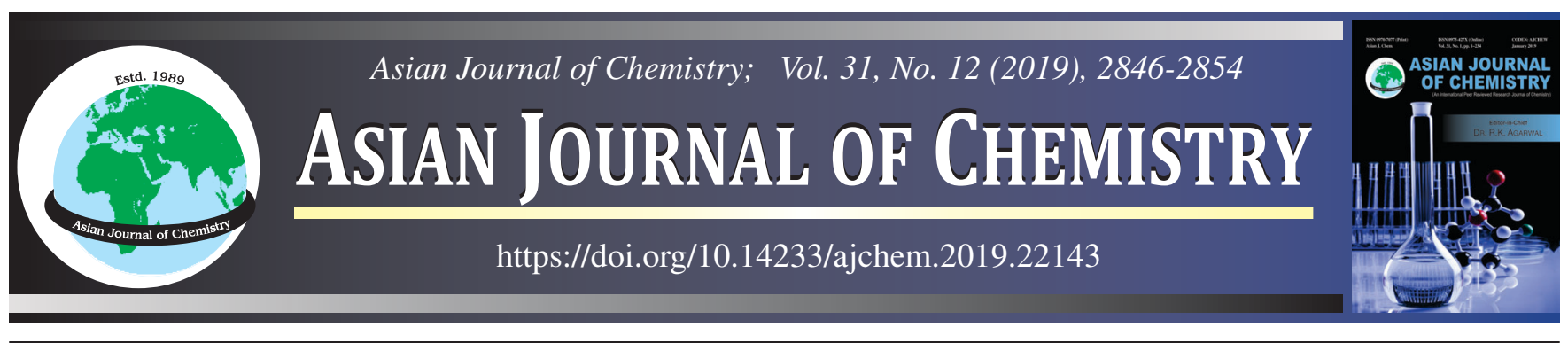

\title{
Synthesis of Metal-Polymer-Semiconductor Diode Using Polyaniline by Chemical Oxidative Method and its Temperature Dependent Electrical Conductivity Behaviour
}

\section{E. Shoba ${ }^{1, *}$, N.Pasupathy ${ }^{1}$, P. ThirunavukKarasu ${ }^{2}$, J. ChandraseKaran ${ }^{3}$ and G. Parthasarathy ${ }^{4}$}

${ }^{1}$ Department of Electronics, Research and Development Centre, Erode Arts and Science College (Autonomous), Erode-638009, India ${ }^{2}$ Department of Electronics, Sri Ramakrishna Mission Vidyalaya College of Arts and Science, Coimbatore-641020, India ${ }^{3}$ Department of Physics, Sri Ramakrishna Mission Vidyalaya College of Arts and Science, Coimbatore-641020, India ${ }^{4}$ Department of Electronics and Communication System, Sri Krishna Arts and Science College, Coimbatore-641008, India

*Corresponding author: E-mail: shobarajendranidp@gmail.com; shobarajendranidp@gmail.com

Received: 23 April 2019; Accepted: 26 July 2019;

Published online: 16 November 2019;

The interfacial layer of pristine polyaniline (PANI) polymer was prepared using chemical oxidative method with $0.2 \mathrm{M}$ concentration formerly, aniline hydrochloride was oxidized with ammonium peroxydisulfate $0.25 \mathrm{M}$ in aqueous medium at $1-2{ }^{\circ} \mathrm{C}$ next to aniline, stirring time and polymerization temperature are considerable causing parameters of polymerization reaction, harmoniously metal polymersemiconductor (MPS) constructions of $\mathrm{Cu} / \mathrm{PANI} / n$-Si Schottky barrier diodes with different acids (HCl, acetic acid, nitric acid and sulfuric acid) was fabricated. The structural analyses of XRD sizes of the elements revealed that the crystal structure of distortion and converted into amorphous nature and SEM revealed that the morphology of pristine PANI powders. The FT-IR spectra confirmed that ammonium peroxydisulfate with pristine PANI along with band formation. The optical property of PANI was analyzed using UV-vis spectra and deliberate with minimum band gap $3.1 \mathrm{eV}$ by means of $\mathrm{HCl}$. The electrical property $\mathrm{I}-\mathrm{V}$ temperature ranges 30 to $120{ }^{\circ} \mathrm{C}$ represents that the maximum average conductivity obtains as $0.70 \times 10^{-2} \mathrm{~S} / \mathrm{cm}$ for $0.2 \mathrm{M} \mathrm{HCl}$. The lowest ideality factor (n) and minimum barrier height $\left(\Phi_{\mathrm{B}}\right)$ values were achieved for $\mathrm{HCl}$ of $\mathrm{Cu} / \mathrm{PANI} / \mathrm{n}-\mathrm{Si}$ Schottky barrier diode (SBDs) under the explanation disorder.

Keywords: PANI, Chemical oxidative method, Bandgap, Electrical property, Schottky barrier diode.

\section{INTRODUCTION}

Polyaniline (PANI) is probably the eldest recognized electro conducting polymer. The excessive interest in research of polyaniline as linked to the discovery of its conductivity in the form of Emeraldine salt and existence of different oxidation procedures [1]. In the literature, several changed ways to produce PANI have been demonstrated, though, aniline is classically chosen as the preliminary monomer. In previous works [2,3], a method to produce polyaniline in the EB form initial from aniline dimer (DANI), which on the contrary to aniline is nontoxic and low-cost, was advanced. In recent years, the growth of inorganic polymer hybrid materials on the nanometer scale has conventional significant attention due to a wide range of potential presentations in optoelectronic devices [4,5]. In general, the synthesis of a hybrid polymer-inorganic material aims to obtain a new composite material with synergetic or complementary behaviours between the polymer and inorganic materials.
It is a most studied polymer because of its relative ease in research, considerable environmental stability $[6,7]$ and tunable conductivity. It has been engrossed in various electronic devices such as electromagnetic interference shielding, anti-electrostatic coatings, rechargeable lightweight batteries, high-density information storing material [8] and conducting polymers are ending a profusion of applications in abundant electronic devices such as electromagnetic interference shielding, anti-electrostatic coatings, rechargeable batteries, chemical sensors and semiconductor devices [9-14]. PANI has been widely studied, due to its ecofriendly stability, redox properties and adjustable nature of its electrical conductivity $[15,16]$. Metal-semiconductor (MS) get in touch with is one of the utmost extensively used rectifying associates in the electronics industry [17-19]. The main goal of this study is to examine whether the polymer, PANI is answerable for the anomalous performance of $\mathrm{I}-\mathrm{V}$ characteristic.

The polymer/inorganic nanocomposites merge numerous properties of the inorganic components such as normal history

This is an open access journal, and articles are distributed under the terms of the Attribution 4.0 International (CC BY 4.0) License. This license lets others distribute, remix, tweak, and build upon your work, even commercially, as long as they credit the author for the original creation. You must give appropriate credit, provide a link to the license, and indicate if changes were made. 
of the taxability's, better process ability of polymers and particularly smart modulus, transparency, surface hardness and heat resistance properties. Therefore, growing research interests have been focused on polyaniline/inorganic nanocomposites. The prepared pristine PANI powder using different acids were synthesized by a chemical oxidative method. The I-V characteristics of these composites at room temperature and also as a role of temperature ranges (300-393 K), voltage ranges (1-10 V) have been studied. Finally, the prepared pristine PANI powders, a metal polymer-semiconductor type Schottky barrier diode, were characterized by optical (FT-IR, UV-vis), structural (XRD, SEM) and electrical properties (I-V).

\section{EXPERIMENTAL}

The desired concentration of PANI with $0.2 \mathrm{M}$ aniline hydrochloride, acetic aniline, nitric aniline, sulfuric aniline and $0.25 \mathrm{M}$ ammonium peroxydisulfate (APS) were prepared (Table-1). All the equipments were cleaned with double deionized water and acetone. A $50 \mathrm{~mL}$ of deionized water in volumetric flask kept on an ice-bath $\left(0-2{ }^{\circ} \mathrm{C}\right)$, added $0.2 \mathrm{M}$ $\mathrm{HCl}$ and $0.2 \mathrm{M}$ aniline. Another $50 \mathrm{~mL}$ of double deionized water with volumetric flask also placed on the ice bath, then added $0.2 \mathrm{M}$ ammonium peroxydisulfate in this flask. Now both solutions were kept separately for $1 \mathrm{~h}$ at $0-2^{\circ} \mathrm{C}$. After $1 \mathrm{~h}$, $50 \mathrm{~mL}$ of aniline $\mathrm{HCl}$ in a beaker, $50 \mathrm{~mL}$ of ammonium peroxydisulfate solution was added by slowly drops by drops to $50 \mathrm{~mL}$ of aniline $\mathrm{HCl}$ solution with continous magnetic stirring. Continued the stirring for $30 \mathrm{~min}$ and during this process, the solution colour was changed to dark green. After that the solution was covered with aluminum foil and kept in the freezer for $24 \mathrm{~h}$.

The precipitated PANI was filtered using Whatman filter paper and washed several times with the help of distilled water in order to eliminate unreacted salts and finally with acetone. The precipitate was transferred to the watch glass and dried in a oven for $5-6 \mathrm{~h}$ at $60-80{ }^{\circ} \mathrm{C}$. In the process of grinding, the obtained polyaniline with the help of mortar and pestal, we got fine pristine deep green powder of PANI (Table-2). The same procedure was followed by using acetic acid, nitric acid and sulfuric acid to prepare pristine PANI.

TABLE-2

WEIGHT COMPARISON OF SYNTHESIZED PRISTINE POLYANILINE POLYMERS USING DIFFERENT ACIDS

\begin{tabular}{ccccc}
\hline $\begin{array}{c}\text { Weight } \\
\text { conc. }(\mathrm{M})\end{array}$ & $\begin{array}{c}\text { PANI HCl } \\
(\mathrm{g})\end{array}$ & $\begin{array}{c}\text { PANI } \\
\text { acetic acid } \\
(\mathrm{g})\end{array}$ & $\begin{array}{c}\text { PANI nitric } \\
\text { acid }(\mathrm{g})\end{array}$ & $\begin{array}{c}\text { PANI } \\
\text { sulfuric } \\
\text { acid }(\mathrm{g})\end{array}$ \\
\hline 0.2 & 3.2375 & 2.7357 & 8.7271 & 1.7325 \\
\hline
\end{tabular}

Cleaning procedure of silicon wafer: One side elegant $n$-type silicon wafer (100) with a width of $279 \pm 29 \mu \mathrm{m}$ was used as an electrode for the manufacture of Schottky barrier diode (SBDs). The new silicon wafer may has certain supplementary impurities, such as dust, lubricant and metallic impurities on its surface and lead to low efficiency of SBDs.

The $\mathrm{Cu} / \mathrm{PANI} / \mathrm{n}-\mathrm{Si}$ structures were fabricated on a 2 inch diameter $n$-type (P-doped) single crystal silicon wafer with (111) surface orientation, $0.7 \Omega \mathrm{cm}$ resistivity and $3.5 \mu \mathrm{m}$ thickness. So, some cleaning steps of $\mathrm{Si}$ wafers were required [20] as: (a) the wafer was reduced for $10 \mathrm{~min}$ in steaming acetone and ethanol; (b) eliminating organic residues from the substrate using piranha solution $\left(\mathrm{H}_{2} \mathrm{SO}_{4}+\mathrm{H}_{2} \mathrm{O}_{2}\right.$ in the ratio of 3:1); (c) the native oxide layer from $\mathrm{Si}$ wafer was detached by the diluted hydrofluoric acid ( $\mathrm{HF}+\mathrm{H}_{2} \mathrm{O}$ in the ratio of 1:10); (d) finally, in each step, the silicon wafers were rinsed with double distilled water.

\section{RESULTS AND DISCUSSION}

FT-IR analysis: The polymer samples for FTIR analysis were assorted and grind with $\mathrm{KBr}$ powder and compacted into pellets, wherein the sample powder was evenly isolated. Fig. 1 shows the FT-IR outline of PANI using different acids. The superficial to volume ratio (i.e. aspect ratio) for nanoparticles is upper than their bulk counterpart. As more atom/molecules are decided on the surface of the nanoparticle. For instance, $\mathrm{C}-\mathrm{N}$ bonds are moved to the higher wavenumbers which are characteristic nanocomposites while $\mathrm{N}-\mathrm{H}$ is shifted to the lower one which is weaker. The spectrum of pristine PANI exhibited intensive band at 1565, 1480, 1294, 1235, 1079 and $789 \mathrm{~cm}^{-1}$, which describe PANI structure. The peaks of PANI at 1575 and $1494 \mathrm{~cm}^{-1}$ (due to quinoid and benzenoid rings, respectively), and $800 \mathrm{~cm}^{-1}$ (1,4-substituted phenyl ring stretching) which are identical to Emeraldine salt form. A peak at $1658 \mathrm{~cm}^{-1}$ attributed to $\mathrm{C}=\mathrm{C}$ stretching in aromatic nuclei, 1600-1500 $\mathrm{cm}^{-1}$ correspond to $\mathrm{C}-\mathrm{H}$ stretching in aromatic compounds and $1693 \mathrm{~cm}^{-1}$ was due to carbonyl groups $(\mathrm{C}=\mathrm{O})$, which are formed during the thermal change of polymer precursor, 1494, 1461, $1444,1406 \mathrm{~cm}^{-1}$ evidenced to $\mathrm{C}=\mathrm{N}$ stretching in aromatic rings. A band in 1300-1200 $\mathrm{cm}^{-1}$ region corresponds to the C-N stretching of primary aromatic amines while a peak at $1575 \mathrm{~cm}^{-1}$ assigned to the quinoid structure, which did not reveal any important changes for all the polymer samples. Thus, the polymers were organized using di and tribasic acids. A peak at $1242 \mathrm{~cm}^{-1}$, ascribed to $\mathrm{C}-\mathrm{N}^{+}$stretching vibration in the polaron structure is also observed indicated that PANI is in a doped state. The peaks at 3457 and $3230 \mathrm{~cm}^{-1}$ can be attributed to the free (non-

TABLE-1

CHEMICALS USED IN THE SYNTHESIS OF PRISTINE POLYANILINE (PANI) POLYMERS

\begin{tabular}{lccccccc}
\hline & Aniline & $\begin{array}{c}\text { Ammonium } \\
\text { peroxydisulfate }\end{array}$ & Acetone & $\mathrm{HCl}$ & Acetic acid & Nitric acid & Sulfuric acid \\
\hline Company name & Merck & Nice & Spectrum & Rankem & Spectrum & Nice & Merck \\
m.w. $(\mathrm{g} / \mathrm{mol})$ & 93.13 & 228.18 & 58.08 & 36.46 & 60.05 & 63.01 & 98.08 \\
Density $(\mathrm{g} / \mathrm{mL})$ & 1.0217 & 1.98 & - & 1.29 & 1.05 & 1.51 & 1.42 \\
Concentration $(\mathrm{M})$ & 0.2 & 0.25 & - & 0.2 & 0.2 & 0.2 & 0.2 \\
Formula & $\mathrm{C}_{6} \mathrm{H}_{5} \mathrm{NH}_{2}$ & $\left(\mathrm{NH}_{4}\right)_{2} \mathrm{~S}_{2} \mathrm{O}_{8}$ & $\left(\mathrm{CH}_{3}\right)_{2} \mathrm{CO}$ & $\mathrm{HCl}$ & $\mathrm{CH}_{3} \mathrm{COOH}$ & $\mathrm{HNO}_{3}$ & $\mathrm{H}_{2} \mathrm{SO}_{4}$ \\
Quality range & G.R. & L.R. & L.R. & L.R. & L.R. & A.R. & G.R. \\
pH & 6 & 2 & - & 2 & 4 & $<2$ & 2 \\
\hline
\end{tabular}



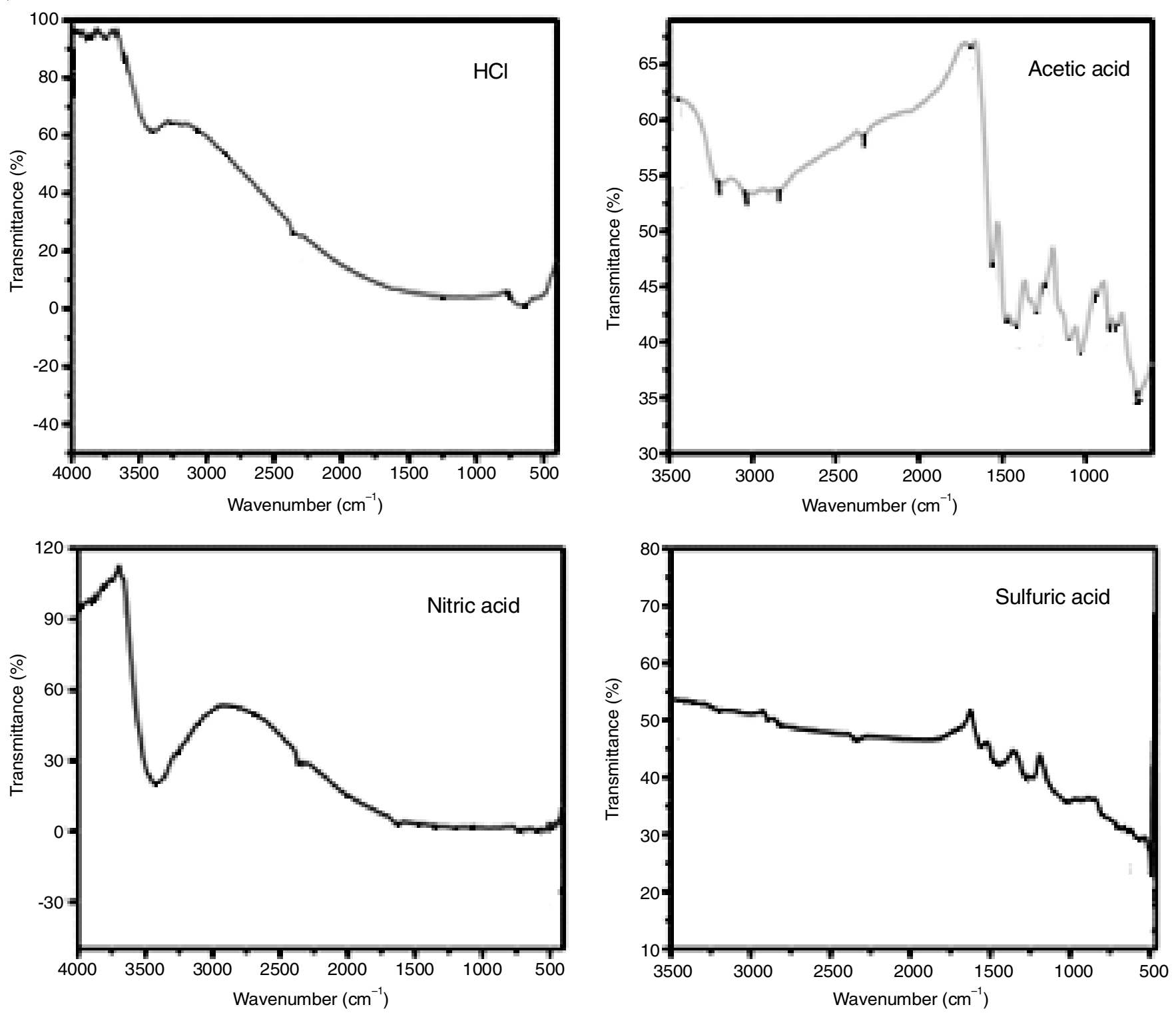

Fig. 1. FT-IR spectra of pristine PANI synthesized with different acids

hydrogen bonded) $\mathrm{N}-\mathrm{H}$ stretching vibration and hydrogenbonded N-H bond between amine and imine sites [21]. The $\mathrm{CH}$ out-of-plane bending mode has been identified as a key to finding the type of substituted benzene. The bands at 1572 and $1489 \mathrm{~cm}^{-1}$ are attributed to the $\mathrm{C}=\mathrm{N}$ and $\mathrm{C}=\mathrm{C}$ stretching mode of vibration for the quinonoid and benzenoid respectively of polyaniline. Similarly, the peaks at 1296 and $1239 \mathrm{~cm}^{-1}$ are assigned to the $\mathrm{C}-\mathrm{N}$ stretching mode of benzenoid ring. The peak at $1239 \mathrm{~cm}^{-1}$ is the representative of conducting protonated form of polyaniline. The bands in the region $1115-1000 \mathrm{~cm}^{-1}$ are due to in-plane bending vibration of $\mathrm{C}-\mathrm{H}$ mode. The bend at $797 \mathrm{~cm}^{-1}$ appeared and assigned as out-of-plane $\mathrm{C}-\mathrm{H}$ bending vibration. It means that acrylic acid had been presented into the polymer chain positively [22-27].

A polymer shows the absorption band $2989,2950 \mathrm{~cm}^{-1}$ is due to asymmetric $\mathrm{C}-\mathrm{H}$ stretching and symmetric $\mathrm{C}-\mathrm{H}$ stretching vibrations. The absorption peaks at 1043, 757, $653 \mathrm{~cm}^{-1}$ in the FT-IR spectra for all samples are reliable with the presence of collection attached aromatic rings. The absorption peaks at $1028,779,645 \mathrm{~cm}^{-1}$ in the FT-IR spectra for all the samples are consistent with the incidence of the group attached aromatic rings [28]. All the four FTIR spectrum shows the validation of the pristine PANI backbone.

Ultra-violet absorption: Fig. 2 shows the assimilation spectrum of polyaniline with $0.2 \mathrm{M}$ using four different acids viz. $\mathrm{HCl}$, acetic acid, nitric acid and sulfuric acid in the visible spectrum. The UV-visible spectrum of PANI depends on the wavelength (nm) and absorption (a.u). The occurrence of strong absorption bands of nearly 295-320, $425 \mathrm{~nm}$ and anprotracted absorption tail in the region of 735-860 $\mathrm{nm}$ in all the four samples. But $\mathrm{HCl}$ is the highest response of absorption peaks in the region $295-320 \mathrm{~nm}$ which relates to the $\pi-\pi^{*}$ changeover of the benzenoid ring segments. While the absorption peak at $425 \mathrm{~nm}$ is assigned to the contained polarons which are the characteristics of protonated PANI. Next to the lengthy absorption tails at $735-860 \mathrm{~nm}$ signifies the conducting PANI [29].

The absorption at $295 \mathrm{~nm}$ arises from the $\pi-\pi^{*}$ excitation of benzenoid ring segments and the absorption at $600 \mathrm{~nm}$ arise from the excitation of quinone diamine structure [30,31]. The 

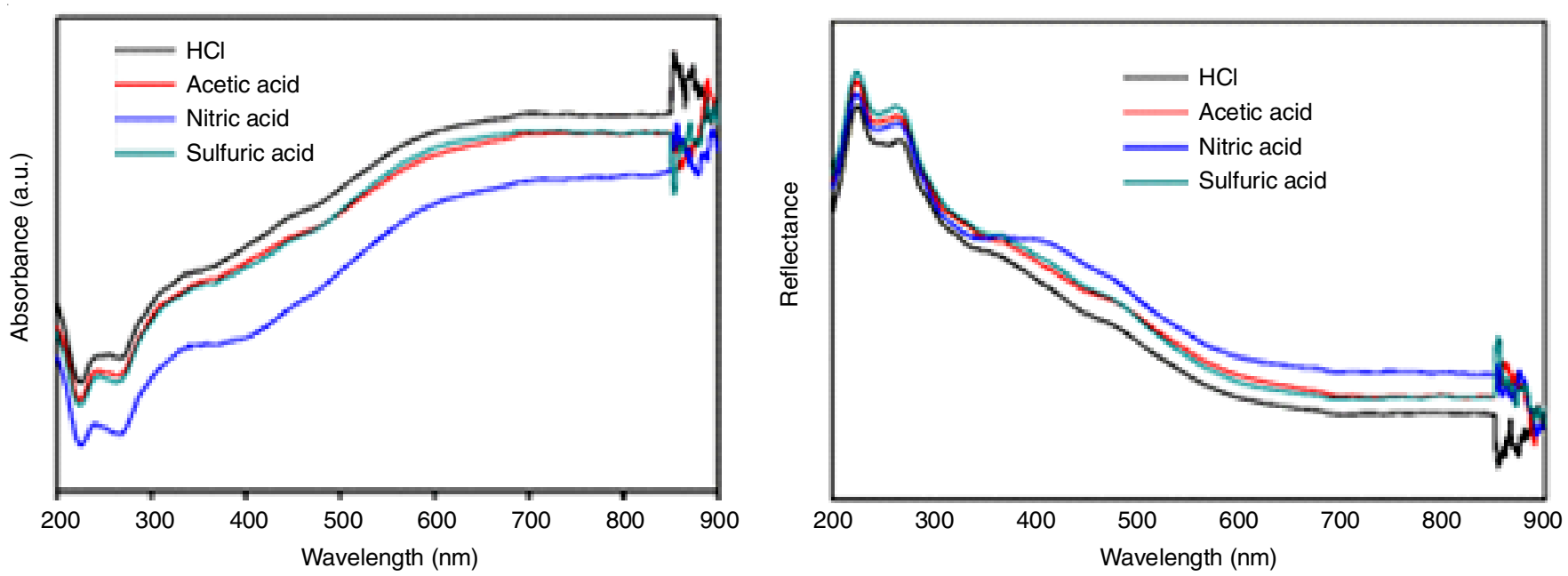

Fig. 2. UV and reflectance spectra of pristine PANI synthesized with different acids

present characteristics bands of polyaniline Emeraldine salt of $320,415,650-690$ which are attributed to $\pi-\pi^{*}$ transition of the benzenoid ring, polaron- $\pi *$ and $\pi$-polaron exaction transition of the quinonoid rings respectively [32]. The broad bands at $600-620 \mathrm{~nm}$ is due to $\mathrm{n}-\pi^{*}$ transitions of quinine-imine groups [33]. The feeble shoulder absorption band at $330 \mathrm{~nm}$ is the $\pi-\pi^{*}$ electron transition of the conjugated aromatic ring. In addition, there is an unremittingly growing free-carrier tail in the close IR region. The exit of this absorption peak band is measured to be correlated to the conductivity of PAN and also indicates the expanded state [34-38].

Band gap: A simple method of calculating the band gap energy of PANI in the powder form using a UV-visible spectrometer. Fig. 3 shows the pristine PANI surface morphology prepared under different acids $(\mathrm{HCl}$, acetic acid, nitric acid and sulfuric acid) having same concentration (0.2 M).

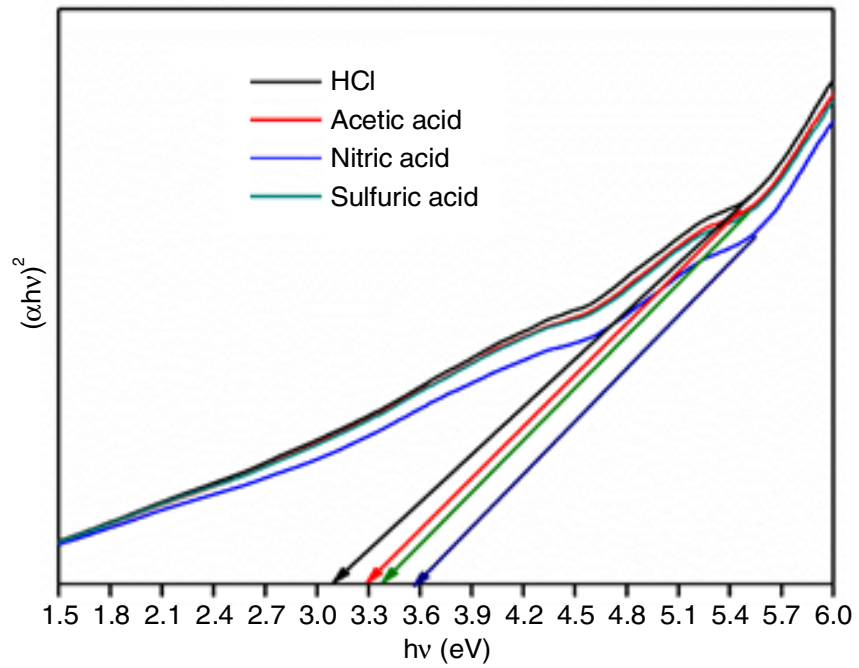

Fig. 3. Band gap graph for pristine PANI synthesized with different acids

SEM analysis: SEM morphology of polymer samples were carried out using scanning electron microscopy (SEM Model: JEOL JSM 6360) working at $20 \mathrm{kV}$. All the samples exhibited the cloudy like structure. These morphological changes with anecdotal oxidation temperature origin the realization of micro-plates, which may be credited to the aggregation or combination of small particles at higher heats. It can be a long range of several tens of micrometers. It signifies that PANI particles have a nucleus effect and core-shell type morphology with a comparatively even diameter of about $20 \mu \mathrm{m}$. Moreover, the oxidative particles would be current not only on the particle surface but also troubled through the interior of the particles, a circumstances relatively similar to that stated elsewhere $[39,40]$. The tendency to cluster formation is also illustrious. There are also free PANI particles in colloid dispersions with lesser size (Fig. 4).

XRD analysis: The XRD patterns of the pristine PANI with different acids are shown in Fig. 5. The X-ray diffractometer (XRD) (XPERT-PRO) With Cuk $\alpha 1$ radiation of wavelength $1.5406 \AA$ at a producer setting of $30 \mathrm{~mA}$ and $40 \mathrm{kv}$ in the $2 \theta$ range from $10^{\circ}$ to $80^{\circ}$ was used to obtain the structure of the PANI powder. The faster growing of polymer results in disorder direction of polymer chains and amorphous polymer structure.

The pattern does not show any perfect or sharp peak characteristics of crystalline materials suggesting usually an amorphous nature for all the polymer samples. This top discernible at the bottom angle $20^{\circ}$ is considered to be the distance between two stacks in the 2-D stacking arrangement of polymer chain with intervening dopant ions [41], In between stacks, while the peak at $10-80^{\circ}, 2 \theta=25^{\circ}$ signifies the characteristics lack of involvement between the ring planes of benzene rings in adjacent chains or the close-contact interchain distance [42].

DC electrical conductivity: The electrical conductivity of PANI samples is shown in Fig. 6. The DC conductivity test was measured using two probe method. Now the sample powder was changed to a pellet form for DC conductivity test. Then increase the temperature ascending order 303 to $393 \mathrm{~K}$, calculate the conductivity for all four samples. Fig. 6 shows the conductivity for PANI prepared from $\mathrm{HCl}$, acetic acid, nitric acid and sulfuric acid with $0.2 \mathrm{M}$. The DC electrical conductivity of samples is pragmatic to be frequency as well as temperature dependent. The frequency dependent conductivity for disordered materials such as polymer can be due to interfacial polarization at contacts and morsel restrictions of the samples [43]. 

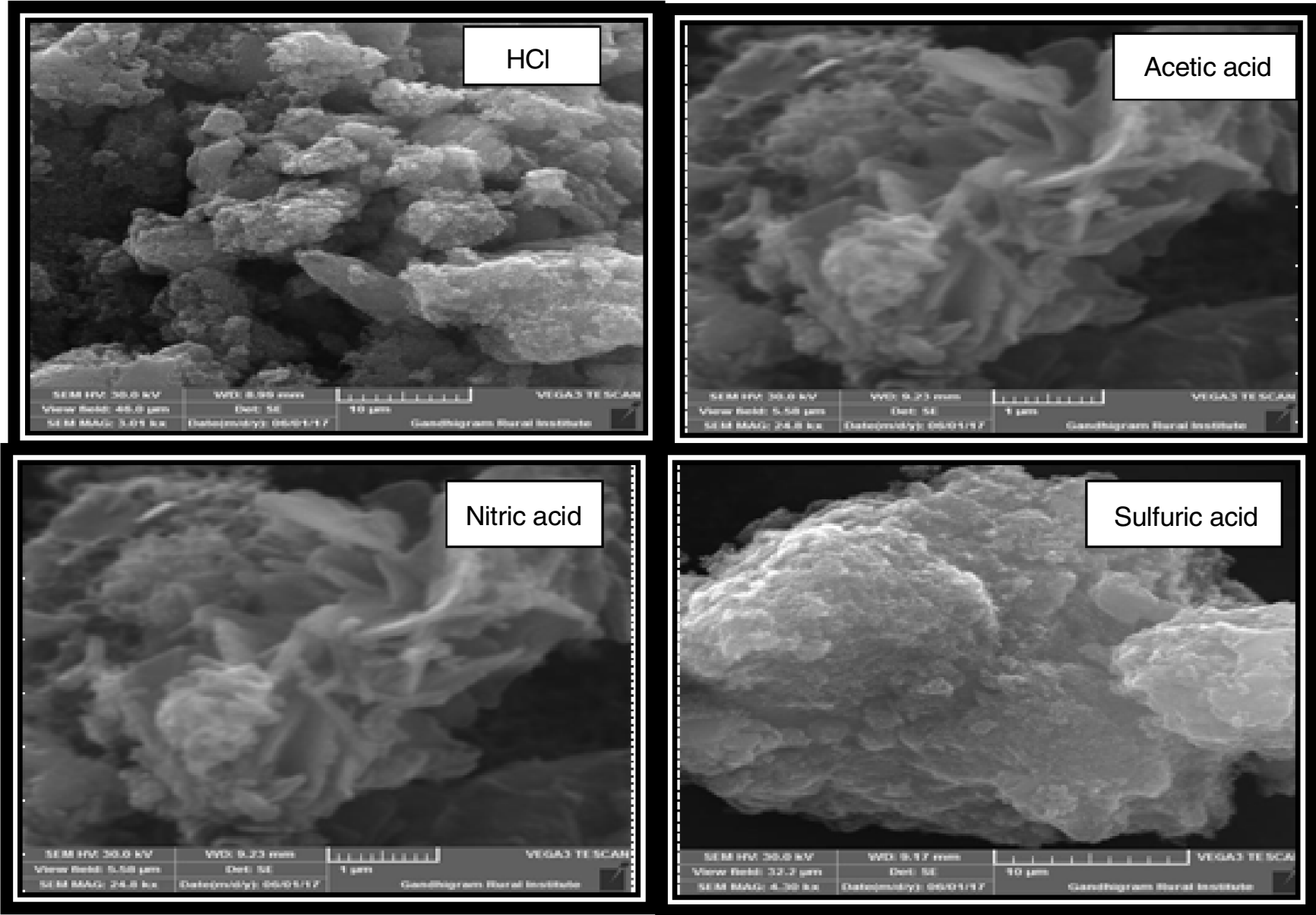

Fig. 4. SEM images for pristine PANI synthesized with different acids

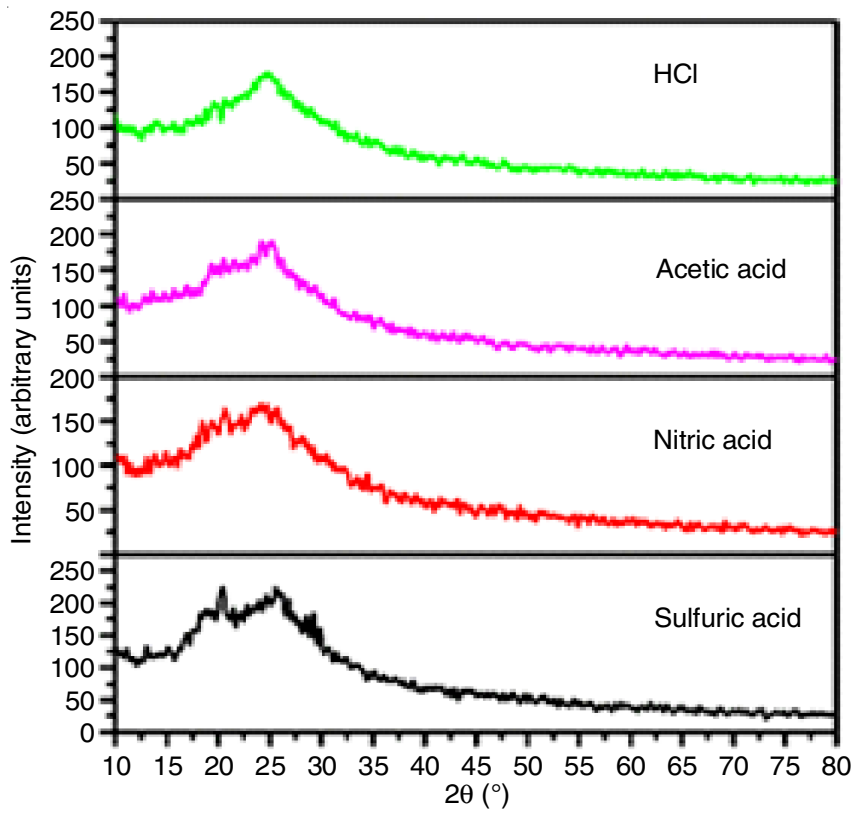

Fig. 5. XRD patterns of pristine PANI synthesized with different acids

The conductivity of pristine PANI exhibits metallic behaviour in which conductivity decreases to some extent with increasing temperature or frequency. It was measured at room temperature by a two-probe method using Keithley (6517B) electrometer. The current values were measured at different applied voltages from 1-10 V. The DC electrical conductivity (O-) for pristine PANI powder was calculated using the given equation:

$$
\sigma=\frac{\mathrm{I}}{\mathrm{V}} \times \frac{\mathrm{d}}{\mathrm{A}}
$$

where, $\mathrm{I}=$ current, $\mathrm{V}=$ applied voltage, $\mathrm{d}=$ inter-probe distance, $\mathrm{A}=$ cross sectional area of the sample.

The DC electrical conductivity of the prepared pristine polyaniline was measured using Keithley electrometer by applying voltage 1-10 V. The conductivity of the samples was deliberate using a two-probe method as a function of the temperature range from 303 to 393 K. Fig. 6 Shows the I-V characterization for pristine polyaniline prepared by various additives such as $\mathrm{HCl}$, acetic acid, nitric acid and sulfuric acid. The electrical conductivity and activation energy of pristine polyaniline was calculated by following the equation.

$$
\sigma_{\mathrm{dc}}=\frac{\mathrm{t}}{\mathrm{RA}}
$$

$$
\sigma=\sigma_{0} \exp \left(\frac{-\mathrm{Ea}}{\mathrm{k}_{\mathrm{B}} \mathrm{T}}\right)
$$

where $t, R, A, K_{B}, \sigma, \sigma_{0}, E_{a}$ and $T$ is the thickness, resistance, active area, Boltzmann constant, conductivity, pre-exponential factor, activation energy and temperature, respectively. As seen from Fig. 6, the current values are increased with the increase 

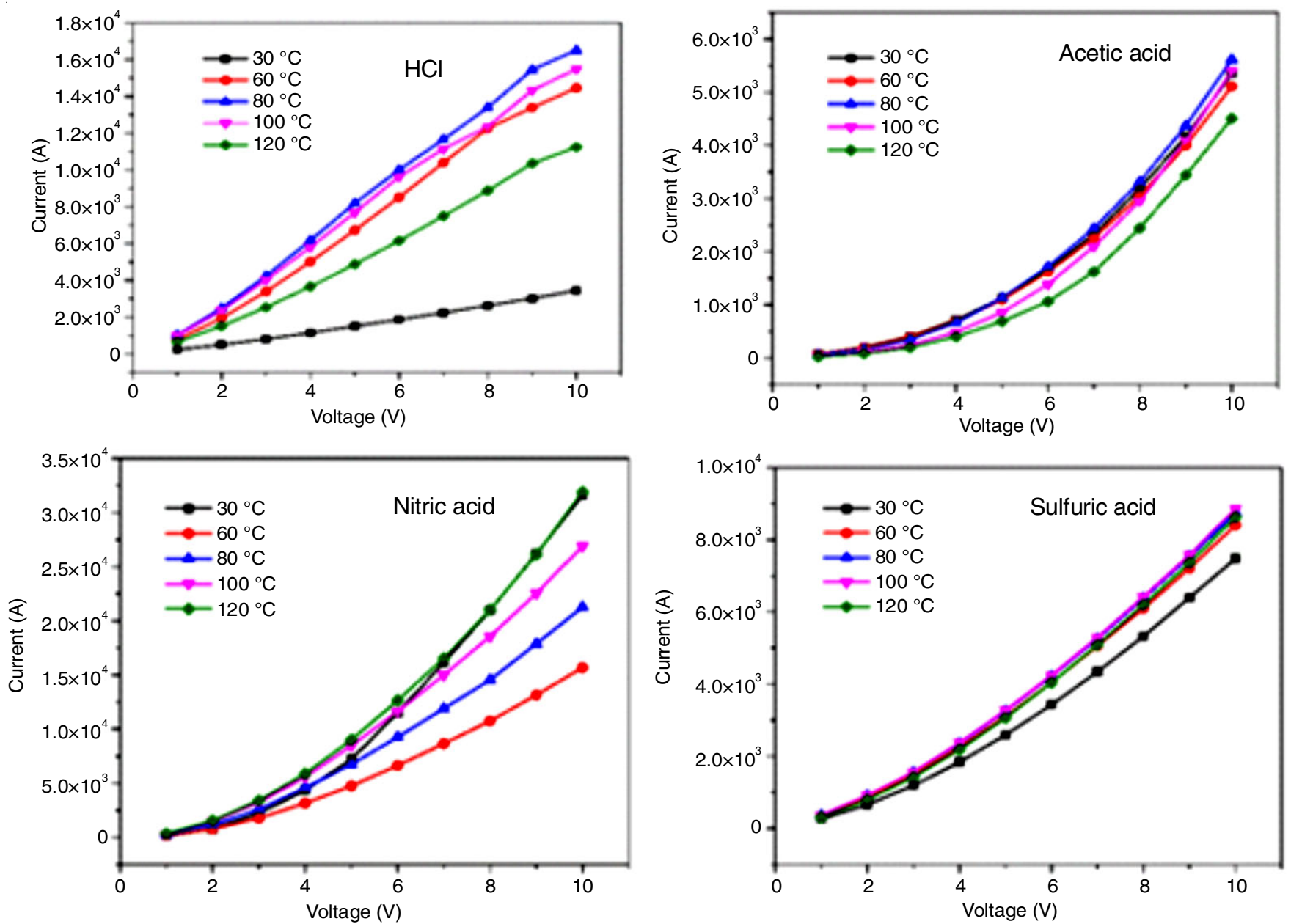

Fig. 6. I-V characterization of PANI treated with different acids for (a) $\mathrm{HCl}$ (b) acetic acid (c) nitric acid (d) sulfuric acid

of applied voltage in all the samples. These results indicate that the prepared pristine polyaniline have a better ohmic behaviour. Moreover, the maximum and minimum average electrical conductivity was obtained for pristine polyaniline condiments of $\mathrm{HCl}$ and nitric acid (Fig. 7). It may be due to the formation of oxygen deficiency in the pristine polyaniline. From these results, all the pristine polyaniline exhibit the semi-conducting nature [44-46]. The maximum activation energy was found for pristine polyaniline having additives of $\mathrm{HCl}$. The estimated

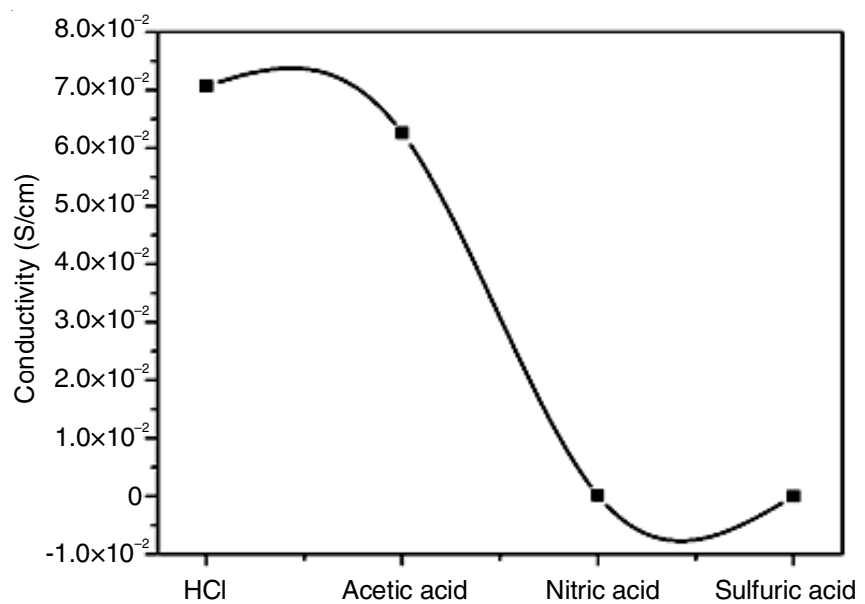

Fig. 7. Average conductivity average of pristine PANI synthesized with different acids values of average conductivity and activation energy are listed in Table-3. From DC electrical study, it is found that the additives strongly affect the electrical parameter.

\begin{tabular}{ccc} 
TABLE-3 \\
AVERAGE CONDUCTIVITY AND ACTIVATION \\
ENERGY OF SYNTHESIZED PRISTINE POLYANILINE \\
POLYMERS USING DIFFERENT ACIDS \\
\hline Additives & Average conductivity & Average activation energy \\
\hline HCl & $0.70 \times 10^{-2}$ & 0.252 \\
Acetic acid & $0.16 \times 10^{-4}$ & 0.142 \\
Nitric acid & $3.88 \times 10^{-5}$ & 0.106 \\
Sulfuric acid & $0.62 \times 10^{-2}$ & 0.216 \\
\hline
\end{tabular}

Fabrication of metal polymer semiconductor (MPS) diodes: As a polymer built organic material, polyaniline (PANI) has been located between $\mathrm{Cu} / \mathrm{n}$-Si MS structure and it has been curved into $\mathrm{Cu} / \mathrm{PANI} / \mathrm{n}-\mathrm{Si}$ MPS structure. The recital and reliability of Schottky barrier diodes (SBDs) are significantly pertinent with the crossing point layer choice for both metalinsulator-semiconductor (MIS) and metal doped polymer semiconductor (MPS) types SBDs [47-50].

The downward curve in curvature region (non-ideal behaviour) of the forward bias I-V plots at a sufficiently huge voltage has an aspect to the presence of not statistically significant, which equilibrates with the semiconductor, apart from the Rs effect of non-aligned region in the Schottky barrier 
diode [51-55]. Likewise, the ideality factor, the barrier height, and the series resistance values have also been firmed by examination in the high current range where the $\mathrm{I}-\mathrm{V}$ characteristic is not linear.

The experimental values of forward and reverse current were measured by applying bias voltage between -4 and $+4 \mathrm{~V}$. Fig. 8 shows the I-V characterization of $\mathrm{Cu} / \mathrm{PANI} / \mathrm{n}-\mathrm{Si}$ type diodes fabricated with different acids. All the metal polymersemiconductor (MPS) diodes exhibit a good rectification nature with better current values in this work.

The current transport mechanism of $\mathrm{Cu} / \mathrm{PANI} / \mathrm{n}-\mathrm{Si}$ SBDs was explained by thermionic emission (TE) theory based on the condition ( $\mathrm{V}>3 \mathrm{kT} / \mathrm{q})$. According to this theory [56,57], the current density (J) of MPS type SBDs was calculated using eqn 4.

$$
\mathbf{J}=\mathbf{J}_{0}\left[\exp \left(\frac{\mathrm{qV}}{\mathrm{nK}_{\mathrm{B}}^{\mathrm{T}}}-1\right)\right]
$$

Where $J_{o}$ is the reverse leakage current density, $q$ is the electron charge, $\mathrm{V}$ is the applied voltage, $\mathrm{n}$ is the ideality factor, $\mathrm{k}$ is the Boltzmann constant and $\mathrm{T}$ is the absolute temperature. Fig. 9 displays the semi-logarithmic plot for MPS diodes. The
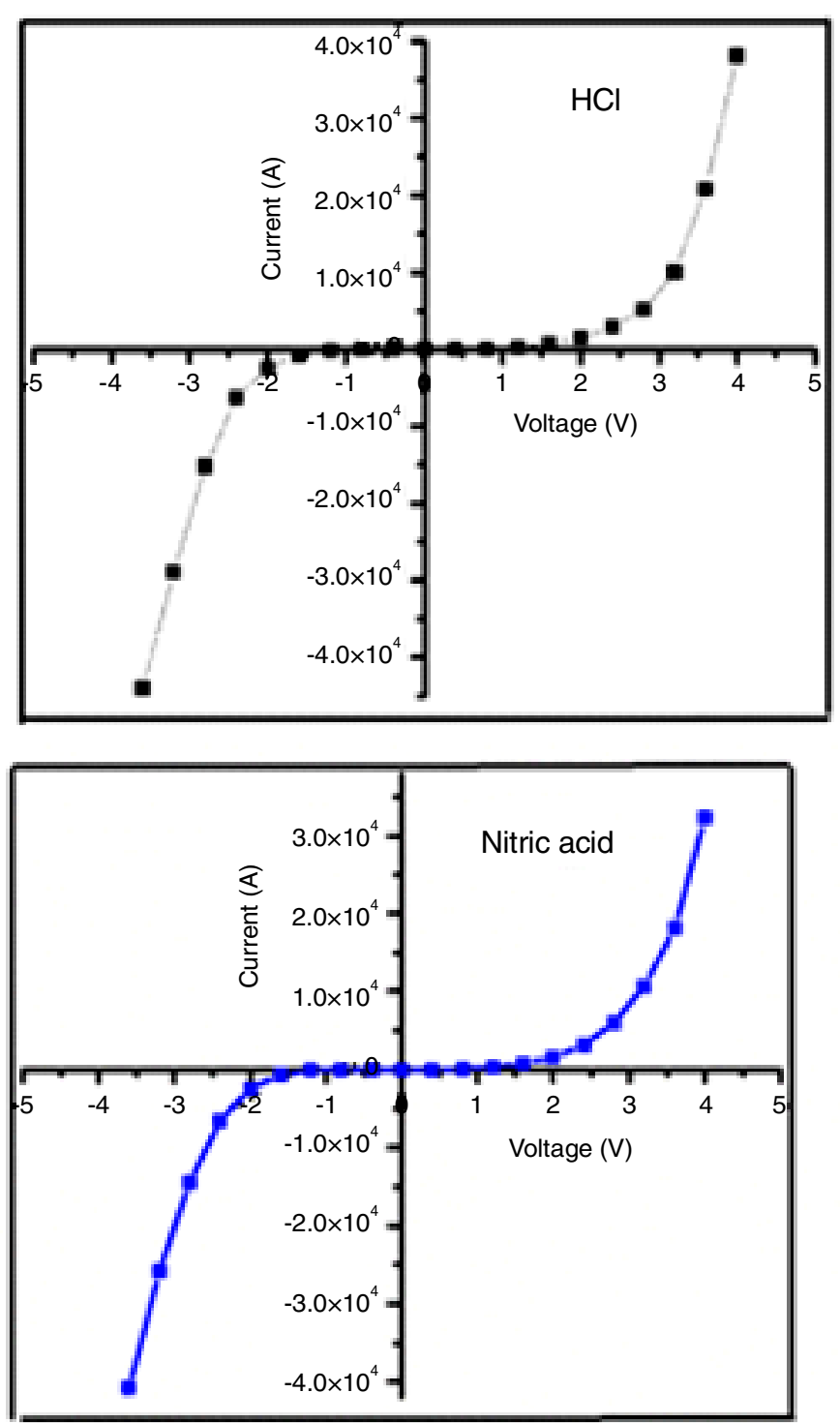

ideality factor (n) value of MPS type SBDs was deduced from the slope and the capture of semi-logarithmic plot. Then and values of the MPS diodes was calculated by eqns 5 and 6 .

$$
\begin{gathered}
n=\frac{q}{k_{B} T}\left(\frac{d(V)}{d(\ln (J))}\right) \\
\Phi_{B}=\frac{k_{B} T}{q} \ln \left(\frac{A A \times T^{2}}{J_{0}}\right)
\end{gathered}
$$

Table-4 shows the estimated values of $n$ for MPS type SBDs. The calculated ideality factors (n) were found to vary from 8.64 to 11.97 and their corresponding barrier height values are 0.659 and $0.657 \mathrm{eV}$, respectively. Remarkably diode fabricated with $\mathrm{HCl}$ shows the low ideality factor of 8.64. However, some MPS diodes exhibited higher ideality factor values like 10 and 11, which may be attributed to the presence of a thin native oxide layer $\left(\mathrm{SiO}_{2}\right)$ in n-type $\mathrm{Si}$ wafer, barrier lateral in homogeneity's, interface states, image force lowering effect, generation of charge recombination and tunneling process. The potential drop across an interfacial layer is also one of the reasons for higher ideality factor [57].
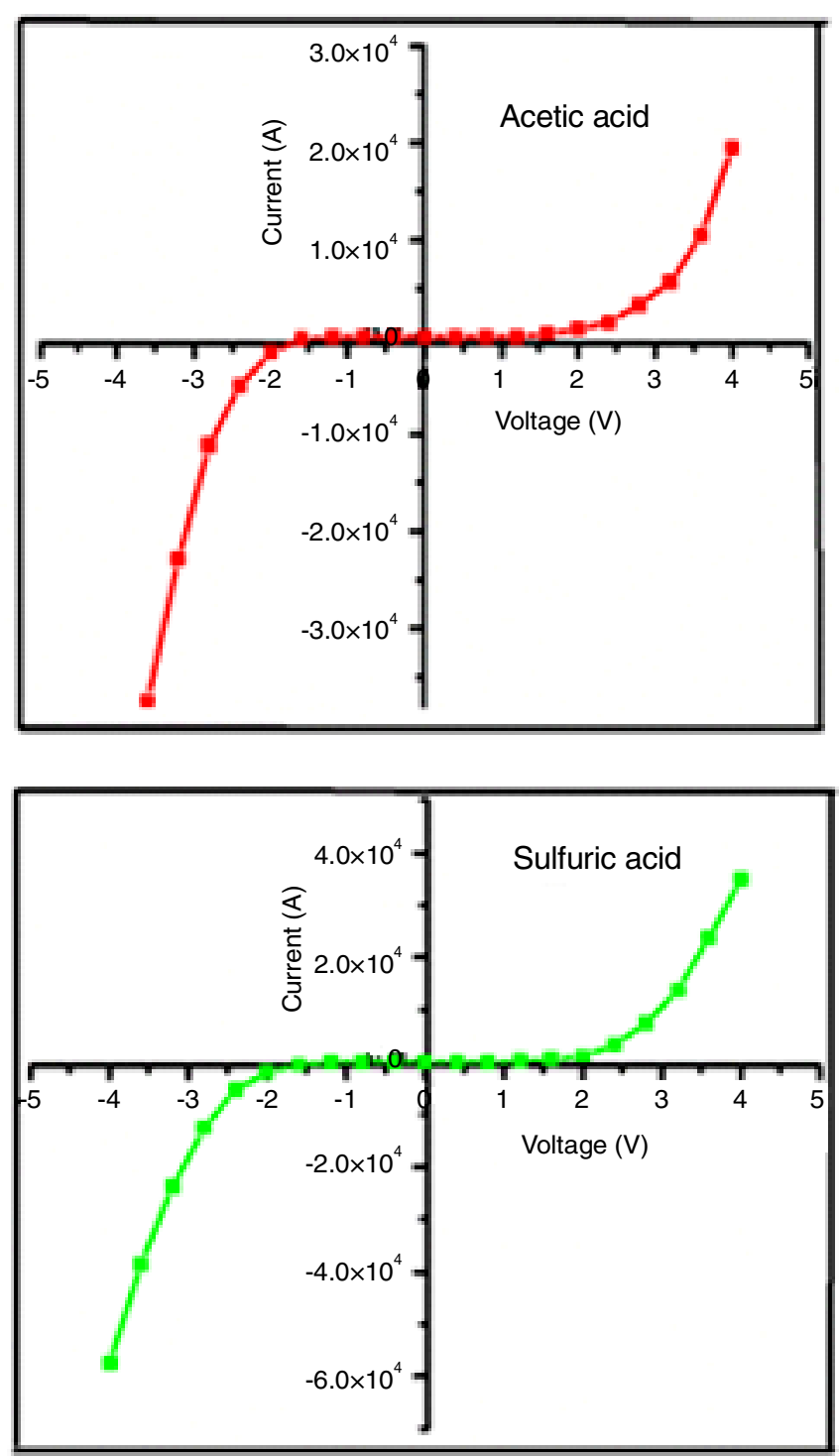

Fig. 8. I-V characterization of $\mathrm{Cu} / \mathrm{PANI} / \mathrm{n}-\mathrm{Si}$ type diodes fabricated with different acids 

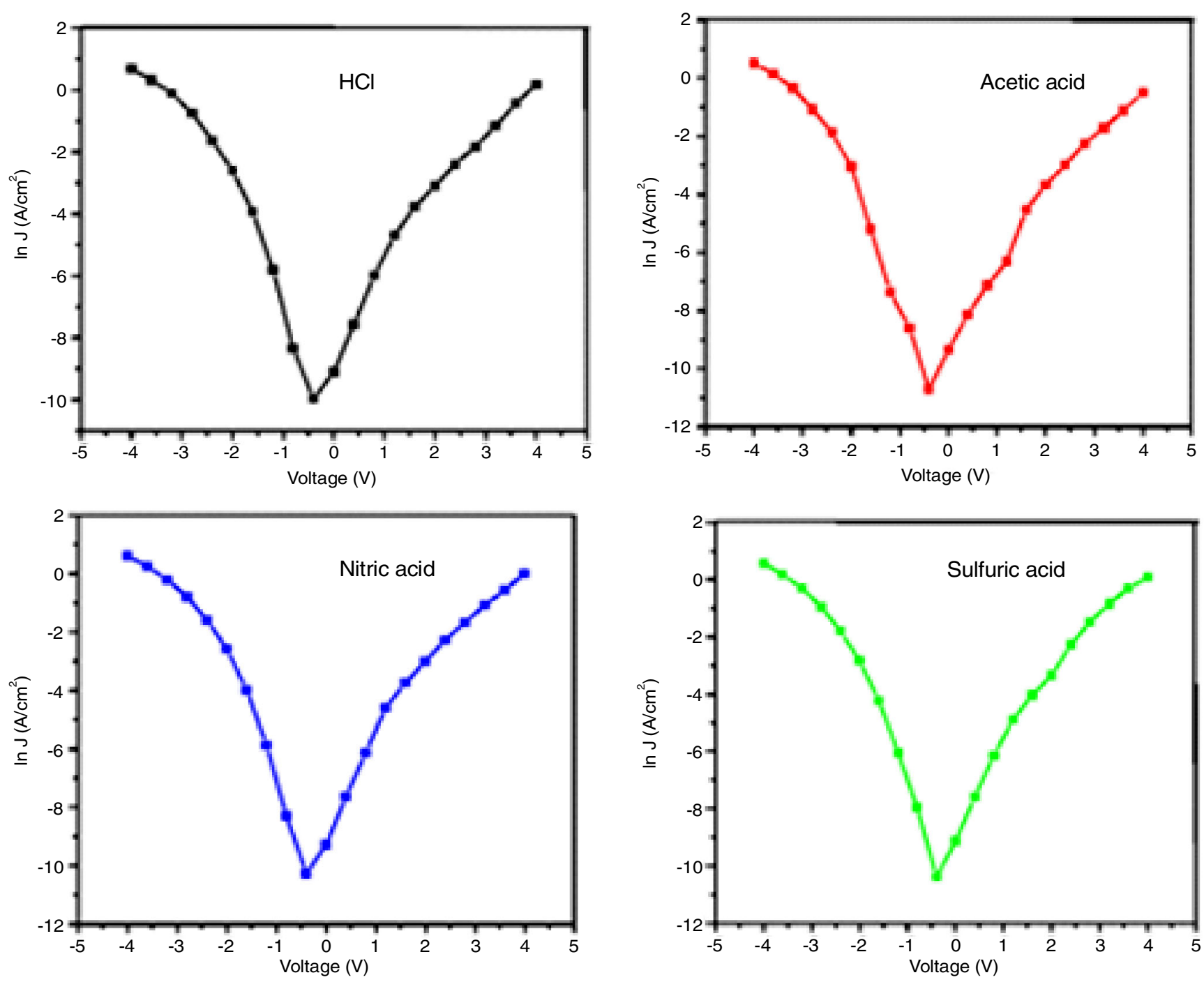

Fig. 9. Plot of $\ln (\mathrm{J})-\mathrm{V}$ for $\mathrm{Cu} / \mathrm{PANI} / \mathrm{n}-\mathrm{Si}$ diodes a pristine PANI with different acids

\begin{tabular}{ccc}
\multicolumn{3}{c}{ TABLE-4 } \\
VARIOUS PARAMETERS VALUE OF \\
Cu/PANI/n-Si SBDs DESIGNED FROM J-V METHOD \\
\hline Four different acids & Ideality factor $(\mathrm{n})$ & Barrier height $\left(\Phi_{\mathrm{B}}\right)$ \\
\hline $\mathrm{HCl}$ & 8.64 & 0.659 \\
Acetic acid & 10.10 & 0.648 \\
Nitric acid & 11.97 & 0.657 \\
Sulfuric acid & 9.72 & 0.651 \\
\hline
\end{tabular}

The ideality factor of $\mathrm{Cu} / \mathrm{PANI} / \mathrm{n}-\mathrm{Si}$ SBDs is determined from the slope and capture of the semi-logarithmic forward bias of $\mathrm{J}-\mathrm{V}$ plot for $\mathrm{V}>3 \mathrm{kT} / \mathrm{q}$ using eqn 4 . From $\mathrm{Cu} / \mathrm{PANI} /$ $\mathrm{n}$-Si results, it should note that organic acids strongly stimulated by MPS type SBDs diodes. However, there are only a few studies on polymer-based SBDs with organic/polymer interfacial layers, which are known as metal polymer semiconductor (MPS) type SBDs [58].

\section{Conclusion}

A pristine PANI polymers were synthesized using chemical oxidative method having $0.2 \mathrm{M}$ concentration of different four acids ( $\mathrm{HCl}$, acetic acid, nitric acid and sulfuric acid) and characterized by FT-IR, UV-visible, SEM, XRD, etc. The FT-IR analysis confirmed the chemical structure of PANI. UV-visible studies confirmed the $\pi-\pi^{*}$ transitions of aniline radical and $\pi-\pi^{*}$ transitions of quinone-imine groups. SEM unveiled the cloudy like structure of the polymer, while XRD revealed that it is amorphous in nature. The electrical conductivity behaviour of polyaniline was also analyzed, when increased the applied voltage, the conductivity also increases. This performance of the voyage of $\mathrm{I}-\mathrm{V}$ curves appears as an idiosyncrasy with respect to the conventional behavior of SBDs. Among all the pristine PANI polymers, $\mathrm{HCl}$ prepared polymer is found to be effective conductivity as compared to polymers prepared from other three acids.

\section{CONFLICT OF INTEREST}

The authors declare that there is no conflict of interests regarding the publication of this article.

\section{REFERENCES}

1. K.M. Molapo, P.M. Ndangili, R.F. Ajayi, G. Mbambisa, S.M. Mailu, N. Njomo, M. Masikini, P. Baker and E.I. Iwuoha, Int. J. Electrochem. Sci., 7, 11859 (2012). 
2. S. Bocchini, A. Chiolerio, S. Porro, D. Accardo, N. Garino, K. Bejtka, D. Perrone and C. Pirri, J. Mater. Chem. C, 1, 5101 (2013); https://doi.org/10.1039/c3tc30764f.

3. A. Chiolerio, S. Bocchini and S. Porro, Adv. Funct. Mater, 24, 3472 (2014); https://doi.org/10.1002/adfm.201470147.

4. B.W.J.E. Beek, L.H. Slooff, M.N. Wienk, J.M. Kroon and R.A.J. Janseen, Adv. Funct. Mater., 15, 1703 (2005); https://doi.org/10.1002/adfm.200500201.

5. X.M. Sui, C.L. Shao and Y.C. Liu, Appl. Phys. Lett., 87, 113115 (2005); https://doi.org/10.1063/1.2048808.

6. D.C. Olson, J. Piris, R.T. Colins, S.E. Shaheen and D.S. Ginley, Thin Solid Films, 496, 26 (2006); https://doi.org/10.1016/j.tsf.2005.08.179.

7. G. Gustafsson, Y. Cao, G.M. Treacy, F. Klavetter, N. Colaneri and A. Heeger, Nature, 357, 477 (1992);

https://doi.org/10.1038/357477a0

8. C. Wang, Y.H. Zhang, J.B. Gao, W.J. Zhang, Y.F. Lu and Y.B. Bai, Chem. J. Chin. Univ., 20, 1491 (1999).

9. M.J. Sailor, E.J. Ginsburg, C.B. Gorman, A. Kumar, R.H. Grubbs and N.S. Lewis, Science, 249, 1146 (1990); https://doi.org/10.1126/science.249.4973.1146.

10. R. Cruz-Silva, L. Arizmendi, M. Del-angel and J. Romero-Garcia, Langmuir, 23, 8 (2007); https://doi.org/10.1021/la0618418.

11. C.H. Yang and Y.K. Chin, J. Phys. Chem. B, 110, 19412 (2006); https://doi.org/10.1021/jp0612174.

12. A. Mirmohseni and R. Solhjo, Eur. Polym. J., 39, 219 (2003); https://doi.org/10.1016/S0014-3057(02)00202-1.

13. S.R. Moraes, D. Huerta-Vilca and A.J. Motheo, Eur. Polym. J., 40, 2033 (2004); https://doi.org/10.1016/j.eurpolymj.2004.05.016.

14. J.Q. Kan, X.H. Pan and C. Chen, Biosens. Bioelectron., 19, 1635 (2004); https://doi.org/10.1016/j.bios.2003.12.032.

15. S. Palaniappan, Eur. Polym. J., 37, 975 (2001); https://doi.org/10.1016/S0014-3057(00)00207-X

16. F. Lux, Polymer, 35, 2915 (1994); https://doi.org/10.1016/0032-3861(94)90402-2.

17. S.M. Sze, Physics of Semiconductor Devices, Wiley: New York, edn. 2, p. 850 (1981).

18. E.H. Rhoderick and R.H. Williams, Metal-Semiconductor Contacts, Clarendon Press: Oxford, edn. 2 (1988).

19. R.T. Tung, Mater. Sci. Eng. R, 35, 1 (2001); https://doi.org/10.1016/S0927-796X(01)00037-7.

20. M. Balaji, J. Chandrasekaran and M. Raja, Mater. Sci. Semicond. Process., 43, 104 (2016); https://doi.org/10.1016/j.mssp.2015.12.009.

21. P.P. Hankare, A.H. Manikshete, D.J. Sathe, P.A. Chate, A.A. Patil and K.M. Gardkar, J. Cryst. Growth, 311, 3386 (2009); https://doi.org/10.1016/j.jcrysgro.2009.04.012.

22. W. Zheng, M. Angelopoulos, A.J. Epstein and A.G. MacDiarmid, Macromolecules, 30, 2953e5 (1997); https://doi.org/10.1021/ma9700136.

23. J.W. Chavalier, J.Y. Begeron and L.H. Dao, Macromolecules, 25, 3325 (1992); https://doi.org/10.1021/ma00039a001.

24. M. Leclerc, J. Guay and L.H. Dao, J. Electroanal. Chem., 251, 31 (1988); https://doi.org/10.1016/0022-0728(88)80382-6.

25. J.Y. Bergeron, J.W. Chavalier and L.H. Dao, J. Chem. Soc., Chem. Commun., 180 (1990); https://doi.org/10.1039/c39900000180.

26. M.T. Nguyen, P. Kassi, J.L. Miller and A.F. Diaz, Macromolecules, 27, 3625 (1994); https://doi.org/10.1021/ma00091a026.

27. V. Prevost, A. Petit and F. Pla, Synth. Met., 104, 79 (1999); https://doi.org/10.1016/S0379-6779(99)00009-0.

28. J. Stejskal, I. Sapurina and M. Trchova, Prog. Polym. Sci., 35, 1420 (2010); https://doi.org/10.1016/j.progpolymsci.2010.07.006.

29. X. Gong, L. Dai, A.W. Mau and H.J. Griesser, J. Polym. Sci. A, 36, 633 (1998); https://doi.org/10.1002/(SICI) 1099-0518(199803)36:4<633::AIDPOLA12>3.3.CO;2-2.
30. D.M. Mohilner, R.N. Adams and W.J. Argersinger, J. Am. Chem. Soc., 84, 3618 (1962); https://doi.org/10.1021/ja00878a003.

31. N. Gospodinova, L. Terlemezyan, P. Mokeva and K. Kossev, Polymer, 34, 24334 (1993); https://doi.org/10.1016/0032-3861(93)90834-W.

32. W.S. Huang and A.G. MacDiarmid, Polymer, 34, 1833 (1993); https://doi.org/10.1016/0032-3861(93)90424-9.

33. W.M. Xiay and A.G. MacDiarmid, Chem. Mater, 7, 443 (1995); https://doi.org/10.1021/cm00051a002.

34. J. Stejskal, D. Lavata, P. Holler, M. Trchova, J. Prokes and I. Sapurina, Poly Int., 53, 294 (2004); https://doi.org/10.1002/pi.1406.

35. A.P. Monkman and P. Adams, Synth. Met., 41, 627 (1991); https://doi.org/10.1016/0379-6779(91)91146-2.

36. M. Ohira, T. Sakai, M. Takenchi and Y. Kobayashi, Synth. Met., 18, 347 (1987); https://doi.org/10.1016/0379-6779(87)90903-9.

37. Y. Furkawa, T. Hara, Y. Yyodo and I. Harada, Synth. Met., 16, 189 (1986); https://doi.org/10.1016/0379-6779(86)90111-6.

38. J.W. Orton, The Story of the Semiconductor, Oxford University Press Inc.: New York (2004).

39. Y. Cheng, S.H. Yang and C. Hsu, Chem. Rev., 109, 5868 (2009); https://doi.org/10.1021/cr900182s.

40. M. Biswas, S.S. Ray and Y.P. Liu, Synth. Met., 105, 99 (1999); https://doi.org/10.1016/S0379-6779(99)00049-1.

41. S.S. Ray and M. Biswas, Synth. Met., 108, 234 (2000); https://doi.org/10.1016/S0379-6779(99)00258-1.

42. J.P. Pouget, Z. Oblakowski, Y. Nogami, P.A. Albony, M. Laridiani, E.J. Oh, Y. Min andA.J. Epstein, Synth. Met., 65, 131 (1994); https://doi.org/10.1016/0379-6779(94)90174-0.

43. J.P. Pouget, C.H. Hsu, A.G. Macdiarmid and A.J. Epstein, Synth. Met., 69, 119 (1995); https://doi.org/10.1016/0379-6779(94)02382-9.

44. R. Patil, A.S. Roy, K.R. Anilkumar, K.M. Jadhav and S. Ekhelikar, Composites: Part B, 43, 3406 (2012);

https://doi.org/10.1016/j.compositesb.2012.01.090.

45. E. Erem, M. Karaksha and M. Sacak, Eur. Polym. J., 40, 785 (2004); https://doi.org/10.1016/j.eurpolymj.2003.12.007.

46. H. Tange, A. Kitani and M. Shiotani, Electrochim. Acta, 41, 1561 (1996); https://doi.org/10.1016/0013-4686(95)00408-4.

47. A. Gok and B. Sari, J. Appl. Polym. Sci., 84, 1993 (2002); https://doi.org/10.1002/app.10487.

48. T.T.A. Tuan, D.H. Kuo, C.C. Li and W.C. Yen, J. Mater. Sci. Mater Electron., 25, 3264 (2014);

https://doi.org/10.1007/s10854-014-2012-1.

49. H. Tecimer, A. Turut, H. Uslu, S. Altindal and I. Uslu, Sens. Actuators A Phys., (2013); https://doi.org/10.1016/j.sna.2013.05.027.

50. J. Werner and H. Guttler, J. Appl. Phys., 69, 1522 (1991); https://doi.org/10.1063/1.347243.

51. O. Cicek, H. UsluTecimer, S.O. Tan, H. Tecimer, I. Orak and S. Altindal, Compos. Part B Eng., 113, 14 (2017) https://doi.org/10.1016/j.compositesb.2017.01.012.

52. S. Altindal, S. Karadeniz, N. Tugluoglu and A. Tataroglu, Solid-State Electron., 47, 1847 (2003); https://doi.org/10.1016/S0038-1101(03)00182-5.

53. J.H. Werner and H.H. Guttler, J. Appl. Phys., 691522 (1991); https://doi.org/10.1063/1.347243.

54. N. Tugluoglu, S. Karadeniz and S. Altindal, Appl. Surf. Sci., 239, 481 (2005); https://doi.org/10.1016/i.apsusc.2004.06.015.

55. P. Chattopadhyay, Solid-State Electron., 37, 1759 (1994); https://doi.org/10.1016/0038-1101(94)90223-2.

56. S. Mahendia, P.K. Goyal, A.K. Tomar, R.P. Chahal and S. Kumar, $J$. Electron. Mater, 45, 5418 (2016); https://doi.org/10.1007/s11664-016-4677-0.

57. E.H. Rhoderick and R.H. Williams, Metal-Semiconductor Contacts, Oxford: Clarendon, edn. 2 (1988).

58. R.F. Schmitsdorf, T.U. Kampen and W. Monch, Surf. Sci., 324, 249 (1995); https://doi.org/10.1016/0039-6028(94)00791-8. 